\title{
Electric Corona Discharge Use For Grain Seeds Treatment Before Sowing
}

\author{
E.G. Porsev \\ Novosibirsk State Technical University \\ Novosibirsk, Russian Federation \\ porseve@mail.ru
}

\author{
B.V. Malozyomov \\ Novosibirsk State Technical University \\ Novosibirsk, Russian Federation \\ mbv5@mail.ru
}

\author{
M.V. Rozhkova \\ Novosibirsk State Technical University \\ Novosibirsk, Russian Federation \\ marina.rozhkova.63@mail.ru
}

\begin{abstract}
The paper overviews directions for electrotechnology treatment of grain seeds before sowing. The hypothesis of the germination enhancement of seeds if treated with corona discharge is presented here. Besides, the description of electrotechnology installation and facilities for it, including manufacturing process quality obtained as a result of scientific tests, are also provided in the paper.
\end{abstract}

Keywords-Corona discharge, electricity, current, voltage, electrotechnology.

\section{INTRODUCTION}

The paper is devoted to the technology optimization of grain seeds treatment before sowing through physical methods excluding high tangible costs and providing the staff safety.

The major task of farming has always been and remains an all-out increase of grain seeds production. At the same time, the main factor of the grain productivity increase is a quality upgrading of seed grain.

Meanwhile in Siberian farms no more than $50-60 \%$ of the first and second class seeds on the average are filled up for storage annually. However, the majority of seeds are unconditional by the germination ability, humidity and purity. Such seeds have a low germination readiness and field survival. Thus, the Siberian farms sow up to $30 \%$ of nongrade seed grains annually. The composition of such seeds is characterized by high heterogeneity, but the germination readiness for each respective year is torn between 10 to $90 \%$. Moreover, seeds have a high percentage of injury, frost damage, humidity. As a result, only due to a low quality of seed grains, the field germination is torn between 40 to $85 \%$ affecting the productivity respectively.

Under the farm conditions, the problem of low quality of seed grains is usually solved by the increase of the seed application rate, but the seed waste in this respect is up to 0.6 centner/ha. To be sure, the improving of seed quality, that is their germination enhancement and germinating energy, gives the possibility to reduce the seed application rate and receive an extra yield allowing one not only to reduce costs on the grain production but to increase the closing gain.

One can increase the quality and field germination of viable seeds using the practice of preseeding treatment through physical, chemical and other methods. Numerous research data reveal that different types of action on seeds influence positively the up-regulation evolution of plants. Therefore, currently satisfiers fostering the germinating energy enhancement and field germination rate of seed grain have been widely used in agricultural practice. The easiest way used in most farms for improving sowing qualities of seeds is pretreatment, solar heating and preseeding warm-up in aerated bins or seed driers. In addition, the studies of seed treatment with gamma radiation, super-high frequencies, infrared rays, thermal and magnet radiation fields, including their combinations, were conducted. A positive influence on germinating ability, growth and development of plant and adequately on the yield and its quality gives the grain seed treatment of various crops by electric field [1].

\section{THEORY}

The problem-based situation is the yielding capacity of mentioned technologies is not high, the installation for seed treatment is difficult to make and it is energy-intensive, zero tillage is dangerous for staff. Besides, the majority of developers use the hypothesis of germination stimulation and germinating energy with impact of satisfiers on genetic potential of the seed bud.

The objective of this paper is to increase efficiency of technology installation and crop yield. The following challenges were offered to achieve the stated objective:

1. Machine design development where gravity force is used for transporting seeds in the irradiation zone by corona discharge.

2. Optimum performance development of grain seed treatment. 
3. Physical phenomenon definition of the germination enhancement and readiness of grain seeds if treated with electric current of corona discharge.

The hypothesis at issue was that electric current of corona discharge flowing down the surfaces with smooth curve was concentrated on pathogen spore bodies of pathogenic fungi and it burned them out providing the seed bud with steady growth.

As a result of such treatment a slight lab germination enhancement and readiness as compared to control (by 3-5\%), and sometimes lack of change is observed.

There is also the possibility of negative results with regard to physiologically immature seeds. On the other hand, the germinative power and field germination exceed control by a quantity up to $24 \%$. Thus, the higher the efficiency is, the higher the germination ability is and the lower the germination readiness is. Numerous tests related to seed treatment in corona discharge area prove the germination ability and readiness dependence of grain seeds on the corona discharge field parameters [2]. However, there is no description of interaction effect with thermal current effect of corona discharge up-to-date. Due to the above-mentioned reasons our team tried to find complex connections of the germination ability and readiness of seeds from the field parameters and also parasitic fungi modifications while treating. To conduct experiments an irradiator was mounted in the field of corona discharge. In addition, a comparison test of discharge chambers with pad and needle discharge electrodes was carried out to obtain optimal design requirements. Besides, it is worth noting that most of existing design installations have disadvantages scaring away potential customers such as big materials consumption, low efficiency, inadequate reliability of high voltage circuits etc. It is related to the necessity of forcing seeds to the treatment area. Having organized the seed supply to the treatment area by gravity some design disadvantages are solved at once. One more possible way to solve listed disadvantages is creating of the air working chamber divided into a number of working cavities with pairwise-parallel joint of electrodes [3].

To define the optimal treatment mode and machine design parameters for electrocorona treatment of the seed grain, the parent population factors were singled out which finally could influence more or less the germination enhancement and crop yield. During research, it quickly became clear that the range of stable corona discharge for chambers with pad electrodes is within limits of $(500-600) \mathrm{kV} / \mathrm{m}$, for chambers with needle electrodes it is within limits of $(400-500) \mathrm{kV} / \mathrm{m}$. It is related to end effects and explained as muting of closelypitched corona discharges. Such effect is known in technology as Gas Treatment Station (GTS).

\section{EXPERIMENT}

The slope of curve indicates the prevalence of corona discharge ignition at sharp elements. So in the chamber with needle electrodes a negative corona is ignited because of less mass of electric charge carrier and the corona start is observed at $E=(200-300) \mathrm{kV} / \mathrm{m}$. Further, there is a positive corona igniting when $E=(400-500) \mathrm{kV} / \mathrm{m}$ and has a gentle incline diagram. Due to negative polarity of lying opposite needle electrode, first a negative corona from seeds and spores (as it was in the previous case) takes place when $E=(200-300) \mathrm{kV} / \mathrm{m}$ and then a negative one from needles of lying opposite electrode takes place when $E=(400-500) \mathrm{kV} / \mathrm{m}$.

In this case, the nature of curve is steeper as the process itself is avalanche-type, which is equivalent of physics of processes.

In the chamber with pad electrodes under charged negatively opposed pad electrode, the slope of curve and start of corona ignition $(E=(200-300) \mathrm{kV} / \mathrm{m}$ ) mean definitely that a positive corona from seeds and spores on receiving electrode take place under charged positively opposed electrode. The slope of curve says of a markedly negative corona from seeds and spores. All above-mentioned facts refer to the possibility of corona discharge namely from needles, seeds and spores. Taking into account a thermal current influence of corona discharge on the great majority of pathogenic microflora spores, one may talk of its devastation when performing treatment. (Figure 1, Figure 2).

Whereas it is necessary to have experimental proof of advanced hypothesis, the experiments on the ground for consolidated influence of corona discharge field on the microflora germination ability were in need. They were conducted.

The experiment results were estimated according to 3 categories: germination enhancement, suppression viability rate of pathogenic microflora and germination readiness of seed buds.

The relevance is obvious, pathogenic microflora inhibition should not coincide with seed bud inhibition.

By efficiency of pathogenic microflora suppression (in research given) is meant the difference between empirical and control value of germinated spores quantity at standard sample of 50 seeds referred to control.

Along with above listed functions the efficiency suppression of parasitic fungi for each of the most dominant was under investigation: Bipolarissorokiniana, Fusariumsp, Alternariasp, Penicilliumsp.

The regression analysis of the test data received in the process of experiments with sprouting of treated barley seeds in roll form routinely, carried out with personal computer, 
allows one to obtain beta coefficient, to assess the equation relevance of the process under investigation and standard error of computing.

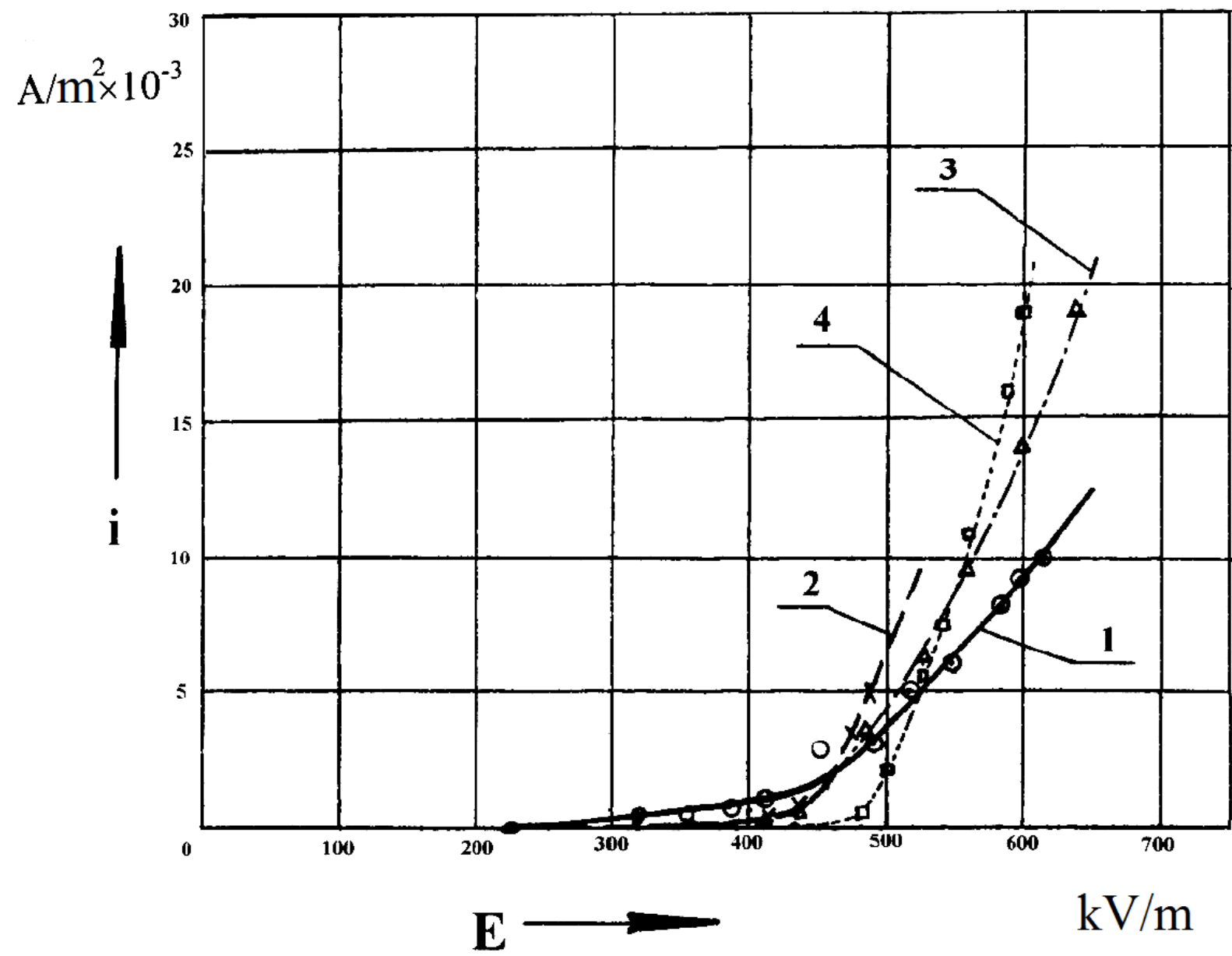

Fig. 1. The volt-amps chamber diagram with needle electrodes: 1- no load operation,(-) on opposed electrode; 2 - no load operation.(+) on opposed electrode; 3barley "Acha" in the gap, (-) on opposed electrode; 4- barley "Acha" in the gap, $(+)$ on opposed electrode.

A complete equation is written as:

$$
\begin{aligned}
& \Delta B_{i}=0.000023 \cdot E+0.000202 \cdot \tau_{e}- \\
& -0.000966 \cdot \tau_{0}-0.469864 \cdot B_{0}- \\
& -1.343358 \cdot j+0.000038 \cdot A+ \\
& +0.005846 \cdot E_{g 1}-0.002566 E_{g 2}- \\
& -0.003305 \cdot E_{g 3}+0.035625 \cdot E_{g 4}- \\
& -0.0000003733 \cdot E \cdot \tau_{e} \cdot \tau_{0}+ \\
& +0.0528 \cdot W_{e m}+0.001396 \cdot F_{k}+ \\
& +0.4519 \pm 0.3233
\end{aligned}
$$

where $\Delta B_{i}$ - germination ability gain, relative unit; $E$ electric-field strength, $k V / m ; \tau_{e}-$ exposure time; $\tau_{0}$ - tempering time; $B_{0}$ - original germination ability, relative unit; $j$ - corona discharge current density, $A / m^{2} ; A-$ heliocosmic unit factor, relative unit; $E_{g 1}$ - suppression rate viability of pathogenic fungi as Bipolaris Sorokiniana, relative unit; $E_{g 2}$ - suppression rate viability of pathogenic fungi as Fusarium, relative unit; $E_{g 3}$ - suppression rate viability of pathogenic fungi as Alternaria, relative unit; $E_{g 4}$ suppression rate viability of pathogenic fungi as Penicillium, relative unit; $W_{e m}$ - quantity of electrical energy wasted in discharger, $k W \cdot h ; F_{k}$ - corona discharge polarity.

The equation analysis shows that some factors are practically nonfactors (meaningfulness is defined according to 
the assessed value principle of slope factor in a value of standard error.

A regression model described by the equation was obtained due to successive exclusion of nonfactors in the equation with specified factors.

$$
\begin{aligned}
& \Delta B_{i}=0.010615 \cdot E-0.022247 \cdot \tau_{0}- \\
& -0.2838 \cdot B_{0}+0.005562 \cdot E_{g 1}+ \\
& +0.02969 \cdot E_{g 4}-0.009935 \cdot W+ \\
& +0.27526 \pm 0.18003
\end{aligned}
$$

It is obvious that all electric field factors $E, \tau_{e}$ and $\tau_{0}$ contribute much to the germination ability gain, and noncontrollable factors contribute to the viability of pathogenic microflora. A regression model shows that microbial products of pathogenic fungi of such kinds as Bipolaris Sorokiniana and Penicillium influence much the barley germination viability.

The test of the equation for research adequacy was performed using Student criterion and it correlates well with the research model.

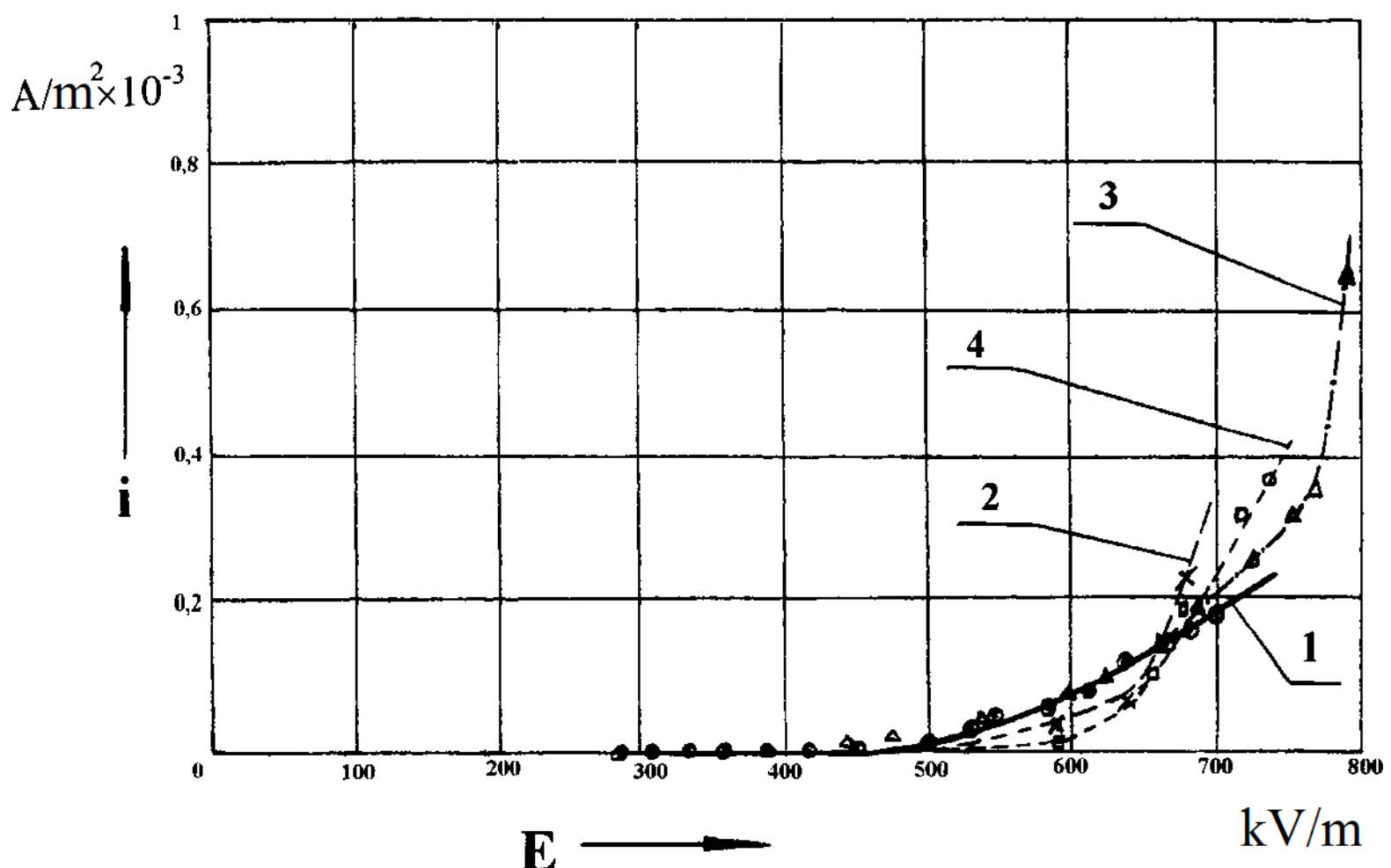

Fig. 2. The volt-amps chamber diagram with pad electrodes: 1- no load operation, (-) on opposed electrode; 2- no load operation, (+) on opposed electrode; 3barley "Acha" in the gap, (-) on opposed electrode; 4- barley "Acha" in the gap, $(+)$ on opposed electrode.

Correlation data mining showed that such factors as $E, j$ and $E \cdot \tau_{0} \cdot \tau_{e}$ correlate relatively pairwise and it corresponds to physics of processes; $\tau_{0}$ and $A_{0}$ also show that total insolation by cosmic rays $A_{0}$ was calculated with regard to astrometeorological data during tempering time.

A regression dependence analysis of suppression viability of pathogenic fungi $E_{g 1}, E_{g 2}, E_{g 3}, E_{g 4}$ on treatment parameters was similarly done. The following regression equations were obtained on reduction:

$$
\begin{aligned}
& E_{g 1}=0.21279 \cdot E-0.11384 \cdot \tau_{e}- \\
& -0.63176 \cdot W_{e m}+0.074471 \cdot F_{k}+ \\
& +0.006679 \pm 0.04701 \\
& E_{g 2}=0,10207 \cdot E+0,3661 \cdot \tau_{e}+0,03167 \cdot F_{k}- \\
& -0,001775 \pm 0,09188 \\
& \quad E_{g 3}=0.30039 \cdot E-0.17796 \cdot \tau_{e}+ \\
& +0.23278 \cdot E \cdot \tau_{e} \cdot \tau_{0}- \\
& -0.003783 \pm 0.08326
\end{aligned}
$$




$$
\begin{aligned}
& E_{g 4}=-0.71848 E \cdot \tau_{e} \cdot \tau_{0}-4.56979 \cdot B_{0}- \\
& -0.271 \cdot W_{e m}+4.44116 \pm 2.0773
\end{aligned}
$$

The factors-parameters of eletrocorona treatment $E, \tau_{e}, W_{e m}, F_{k}$ make great contribution to the suppression viability of pathogenic microflora; a heliocosmic factor does not influence much. The equation analysis of 3-6 enables one to relate the effect of suppression viability to geometry dimension of proper spore kinds (Table 1).
The data analysis states the relation of the suppression viability rate of various fungus strains on electric-field strength at fixed value $B_{0}=0.935 ; W_{e m}=0.156 ; \tau_{e}=0.156 ; \tau_{0}=0.033$

The electric-field strength variation, exposure time, tempering (storing) time, corona polarity, corona current density, heliocosmic factor and fungi suppression viability rate showed that all factors of electric field, including viable microflora factor, make great contribution to the germination ability gain.

\begin{tabular}{|c|c|c|c|c|}
\hline Characteristics & Bipolaris & Fusarium & Alternaria & Penicillium \\
\hline \multicolumn{5}{|c|}{ Spore size, $\mathrm{nm}$} \\
\hline 1) Length & $50-110$ & $5-60$ & $7-72$ & - \\
\hline 2) Diameter & $15-31$ & $2-5$ & $6-22$ & $2-3$ \\
\hline 3) Shape of spore body & cylinder & cylinder & club & sphere \\
\hline \multicolumn{5}{|c|}{ Treatment parameters and their effect on pathogenic fungi suppression viability } \\
\hline 1) Length & $50-110$ & $5-60$ & $7-72$ & - \\
\hline 2) Diameter & $15-31$ & $2-5$ & $6-22$ & $2-3$ \\
\hline 2) Diameter & $15-31$ & $2-5$ & $6-22$ & $2-3$ \\
\hline 2) Diameter & $15-31$ & $2-5$ & $6-22$ & $2-3$ \\
\hline 3) Shape of spore body & cylinder & cylinder & club & sphere \\
\hline
\end{tabular}

TABLE I. GEOMETRY DIMENSION RELATION OF FUNGI SPORES WITH SUPPRESSION EFFECT OF ITS VIABILITY BY ELECTROCORONA DISCHARGE

The relations of germination ability and barley seed growth rate with electrocorona treatment parameter performing have also been studied. The germination ability growth rate particularly defines the effect of corona discharge factors on seeds against pathogenic microflora. The germination ability growth and development rates were computed due to the rate of sprout appearance and development of plant through equal periods of time. The suppression viability rate of pathogenic fungi was defined as quantity difference ratio of sprouted spores in test and check samples to the quantity of sprouted spores in check samples. Mycological and agronomical analyses were run in all samples and variations of experimental design. A computer-aided statistic analysis was performed according to experimental results (Figure 3).

As a result of conducted research, it emerged that there is evident suppression viability relation of pathogenic microflora and germination ability in the chamber with pad electrodes, and this confirms the main hypothesis of the research [7, 8].

Practically the effect does not depend on electric-field strength and exposure time. In the chamber with needle electrodes, an electric-field strength influences additionally [9, 10]. Production inspection with barley under conditions of seed farm produced the following results: if treated with electric current of corona discharge and field strength $(500-512) \mathrm{kV} / \mathrm{m}$ and current density $(0.0043-0.0098) A / m^{2} \cdot 10^{3}$, germination ability gain was $(2.6-3.2) \%$ and correspondently harvest gain was $(16-19) \%$ to harvest in test area 30.2 centner/ha.
Thus the novelty of research results is:

1) in obtaining statistic regression germination ability relation versus electric field parameters with corona discharge, time of tempering spore viability of pathogenic mycoflora and quantity of electric energy dissipated in discharger;

2) in experimental proof of suppression viability of pathogenic mycoflora with electrocorona treatment;

3 ) in experimental hypothesis confirmation of germination enhancement with preseeding treatment using corona discharge due to pathogenic mycoflora suppression.

Figure $4 \mathrm{a}$ and Figure $4 \mathrm{~b}$ show the structure of electric installation for treating seeds. This set contains seed tanker; frame-mounted plate-type electrode cassettes, which are, parallel and angled. They form a series of working cavities for treating seeds in corona discharge [3]. Electrodes next to working cavities are combined. Plates are made from conductive material.

Corona discharge-field electrodes are made in the form of peaked lugs at low sides of cassette-plates, but power-supply source poles are connected with cassette-plates in pairs and parallel. Cassette-plates made from conductive material acting simultaneously as discharge and collector plate electrodes in neighboring working air-gaps of radiation chamber allow one to simplify the working chamber design and owing to its tilted installation to increase efficiency set limits to seed slip velocity over the collecting electrode surface [4].

It was found that the germination enhancement and readiness effect after electrocorona treatment appears as a result of pathogenic mycoflora suppression dwelling on seeds 
due to electric current thermal effect of corona discharge, flowing through microflora spores (fungi or bacteria) because of electric flux condensing in bodies of spores with greater inductive capacity and greater flexure interface of these bodies and environment [5]. The relation of suppression viability of pathogenic microflora and germination enhancement, readiness and rate was obtained as part of the study [6].

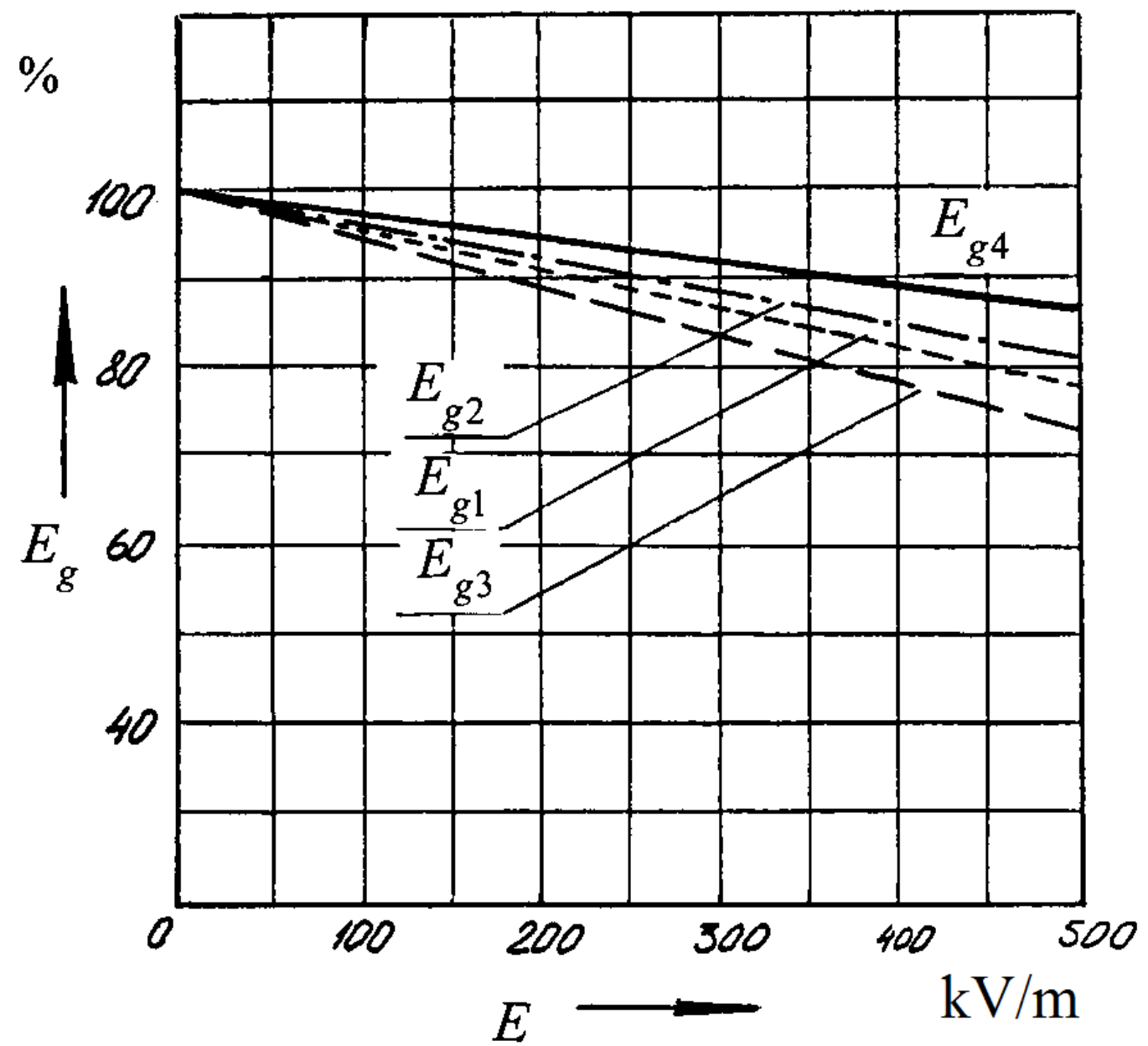

Fig. 3. Suppression rate mycoflora viability relation versus electric-field strength at: $B_{0}=0.935 ; W_{e m}=0.156 ; \tau_{e}=0.156 ; \tau_{0}=0.033$; $E_{g 1}$ - viability of Bipolaris Sorokiniana; $E_{g 2}$ - viability of Fusarium; $E_{g 3}$ - viability of Altemaria; $E_{g 4}$ - viability of Penicillium.

Pathogenic microflora inhibition on spores takes place as electric flux is thickened in interelectrode space area on which the electric field is put, and it is filled either with conductive material (living bacteria, fungi, insects, small deer) or material with greater inductive capacity than the rest part of space. Besides, the electric flux condensing takes place at the environment interface with maximum interface flexure.

As a result, electric current energy of corona discharge is dissipated throughout spores and it warms them up and sterilizes reducing its part in germ pore microcenosis but the use of embedded particles as discharge electrodes allows to decrease power losses caused by electric current through the machine design.
The calculation shows that in case of increasing productivity by $10 \%$, an annual economic benefit in the West Siberia context in one farm having crop acreage of about 10000 hectares will be over 1 million rubles. So, it could be said that the selling value limit of the installation is over 1.7 million rubles, taking into account the real cost the installation will pay off in spades in the first year in use.

\section{CONCLUSIONS}

1. It is wise to design the chamber construction as a series of plates-collecting electrodes mounted on the slope for seed free flow and with discharge electrodes backside.

2. All electric field parameters contribute much to the germination enhancement: electric field strength, exposure time, tempering time including uncontrolled factorspathogenic mycoflora viability. Values of factors are experimentally chosen for each seed lot. 
3. The germination enhancement and readiness effect after electrocorona treatment emerges as a result of pathogenic mycoflora suppression dwelling on seeds due to thermal action of electric current of corona discharge flowing mainly through spores of myco- and microflora owing to electric flux condensing in bodies of spores with greater inductive capacity and greater flexure interface of these bodies and environment. The suppression viability of pathogenic mycoflora results in germination enhancement, readiness and rate.

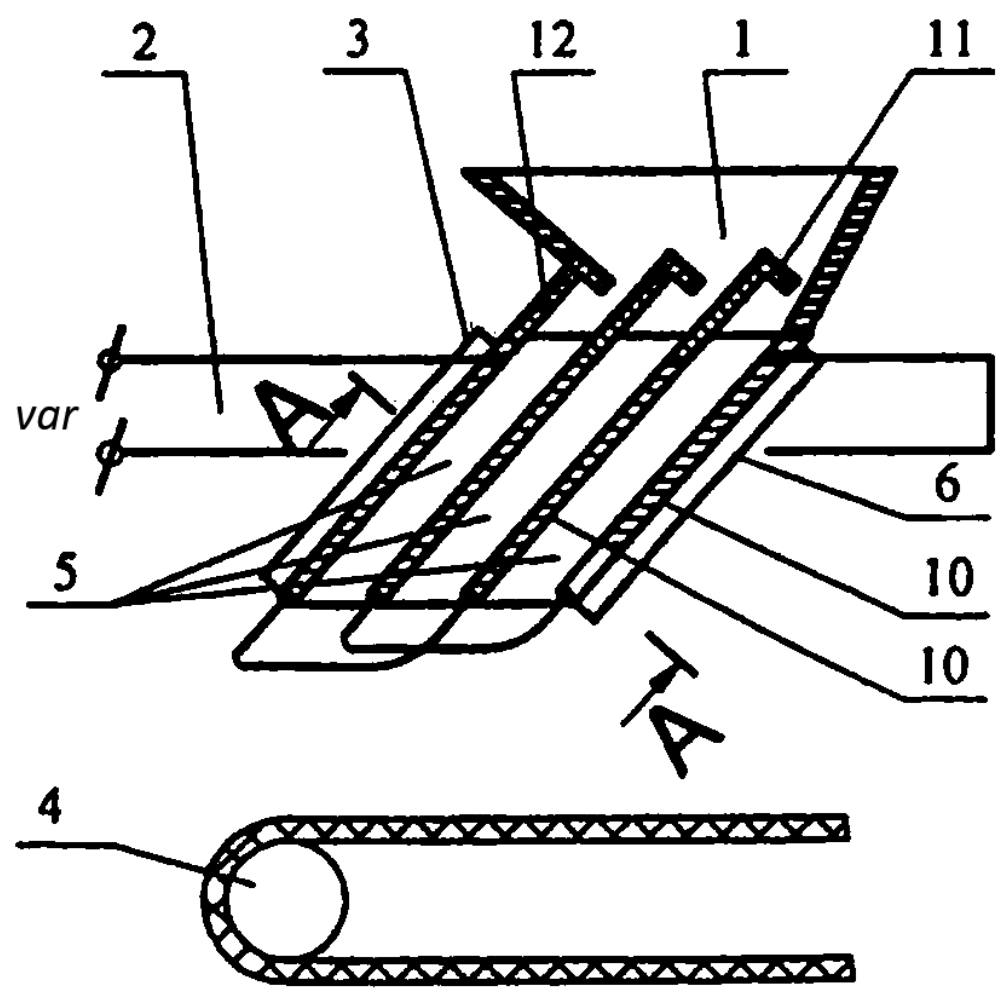

Fig. 4a. Electric installation (set) structure to treat seeds: 1- charging hopper for seeds, 2 - DC power supply system, 3 - cable, 4 - transporter, 5 - runner, 6 - cable, 10 - electrodes, 11 - stop plate, 12 - body dielectric.

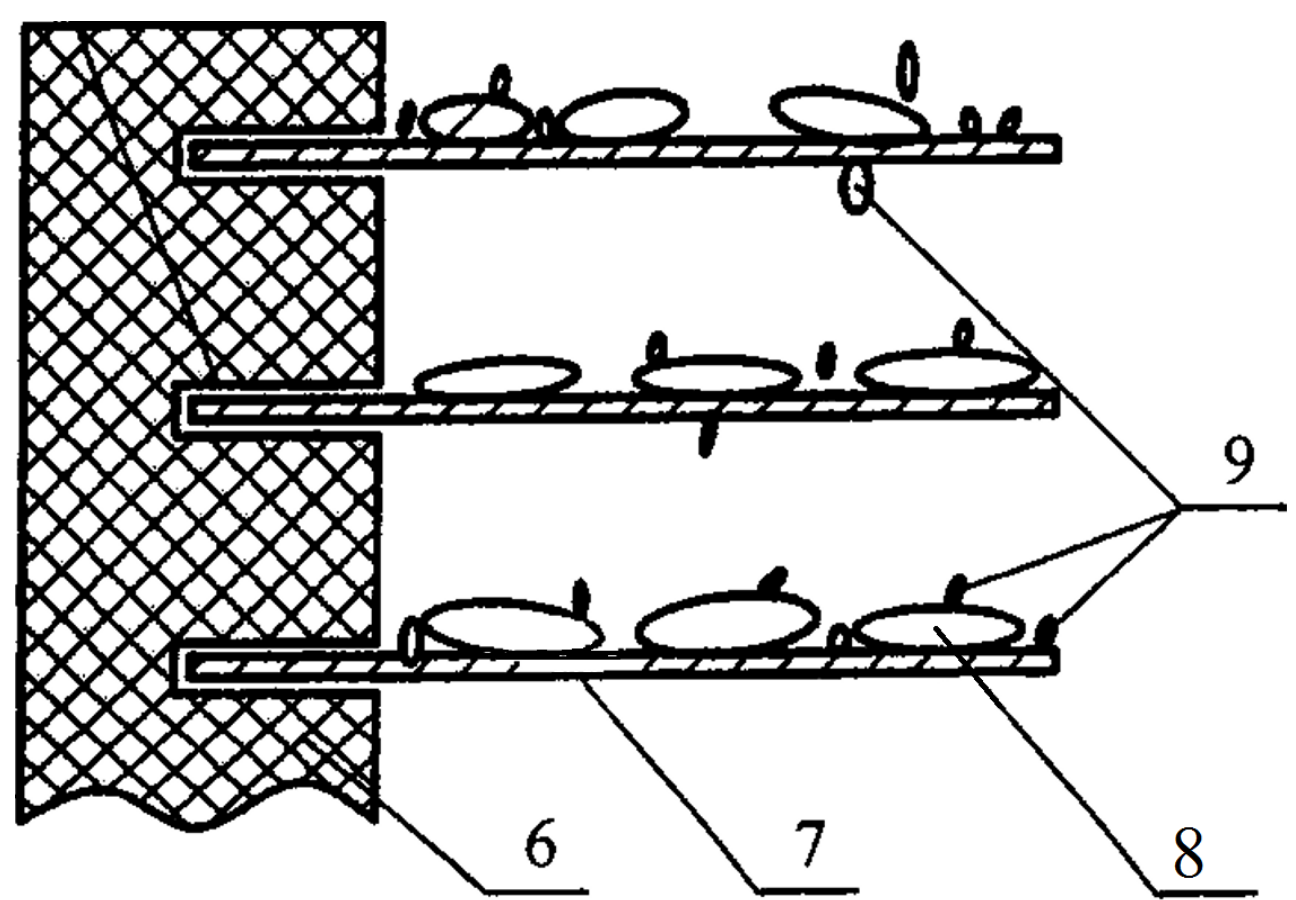

Fig. 4b. Electric installation to treat seeds: 6- dielectric base, 7- runner guides, 8 - seeds, 9 - fungi spore. 


\section{References}

[1] B.A. Arzhannikov and A.A. Pyshkin, "Improving of DC power supply system based on automatic voltage regulation of traction substations (Sovershenstvovanie sistemi elektrosnabzheniya postoyannogo toka na osnove avtomaticheskogo regulirovaniya napryazheniya tyagovih podstanciy)", Ekaterinburg: "USURT Press", 2006, 116 p.

[2] V.I.Sopov, V.V. Biryukov, Y.A. Prokushev and Y.A. Rylov, "Analysis of power supply systems for rolling stock with various schemes of traction networks (Analiz sistem elektrosnabzheniya podvizhnogo sostava s razlichnimi shemami tyagovih setey)", Transport, Science, Engineering, Management (Transport, Nauka, Technika, Upravlenie). Vol. 2 (2008), pp. 49-53. [Digest of the VINITI RAS]

[3] N.I. Schurov, E.A. Spiridonov and A.V Larin, "Modes of traction power supply system in case of electric rolling stock equipped with energy storage", Applied Mechanics and Materials, Vol. 698, pp. 19-23, 2014.

[4] Photovoltaic (PV) research: National Renewable Energy Laboratory (NREL). Retrieved on http://www.nrel.gov/ncpv.

[5] N.W.A. Lidula and A.D. Rajapakse, "Microgrids research: a review of experimental microgrids and test systems", Renewable and Sustainable Energy Reviews, Vol. 15, pp. 186-202, 2011
[6] B. Kroposki, R. Lasseter, T. Ise, S. Morozumi, S. Papathanassiou and N Hatziargyriou, "A look at microgrid technologies and testing projects from around the world, making microgrids work", IEEE Power and Energy Magazine, Vol. 6, pp. 40-53, 2008.

[7] V.E. Rozenfeld, "Analytical calculation of electric railway networks (Analiticheskiy raschet setey elektricheskih zheleznih dorog)", The theoretical and scientific-practical peer-reviewed journal "Elektrichestvo", Vol. 9, pp. 6-17, 1947.

[8] V. G. Sysenko VG, D.A. Bosvit, E.N. Kosarev, "Improvement of the methodology for calculating the distributed traction power-supply system with an amplifying point", Power electronics and power engineering, vol. 9, pp. 8-18, 2014

[9] O.I. Sablin, "Improving the efficiency of energy recovery in the electric transport system with limited traction power supply", Technological audit and production reserves, vol. 5/1, pp. 21-26, 2014.

[10] V.V. Biryukov, A.V. Kulekina, "The calculation features of the electrical energy storage devices parameters in transport", IFOST 2016, pp. 41-43, June 2016 [The 11 International forum on strategic technology, p. 596, 2016]. 
